2009-05

\title{
A National Survey Investigating UK Prescribers' Opinions on Chemotherapy Dosing and 'Dose-Banding'
}

\section{Kaestner, SA}

http://hdl.handle.net/10026.1/3711

10.1016/j.clon.2008.12.004

Clinical Oncology

Elsevier BV

All content in PEARL is protected by copyright law. Author manuscripts are made available in accordance with publisher policies. Please cite only the published version using the details provided on the item record or document. In the absence of an open licence (e.g. Creative Commons), permissions for further reuse of content should be sought from the publisher or author. 


\title{
A National Survey Investigating UK Prescribers' Opinions on Chemotherapy Dosing and 'Dose-Banding'
}

\author{
S. A. Kaestner*, G. J. Sewell † \\ *NHS Plymouth/Plymouth Teaching PCT, Medicines Management Team, Plymouth, UK; \\ †Department of Pharmacy, Kingston University, Kingston upon Thames, Surrey, UK
}

\begin{abstract}
:
Aims: The primary purpose of dose-banding for cancer chemotherapy is to reduce patient waiting times, but dosebanding also has additional benefits, such as reduced drug wastage, reduced stress for staff, and prospective quality control of infusions. However, the uptake of dose-banding seems fairly low. Possible reasons for this are a reluctance to use dose-banding for clinical reasons or a lack of awareness. Despite the seemingly minor change from established practice of dose prep aration, dose-banding has the potential to alter patient chemotherapy exposure. The aim of this study was to investigate prescribers' awareness of dose-banding and their opinions on the scope and limitations of dosebanding in the context of UK chemotherapy services.

Materials and methods: This survey was performed throughout the UK by use of a postal questionnaire, which was validated before national distribution to 1104 oncologists and haematologists. The questionnaire contained both quantitative and qualitative elements. A database was created for data entry and analysis.

Results: The response from prescribers was encouraging for a postal questionnaire, with a $35 \%$ response rate (387 responses). Many were aware of the concept of dose-banding $(>80 \%)$ and were also supportive of the system. The weakness around body surface area-based dosing was a commonly discussed topic. However, opinions on which is the maximum acceptable deviation from the prescribed dose with dose-banding were controversial, and there was a concern about the lack of evidence to support the use of dose-banding. The views on whether carboplatin and targeted therapies should be dose-banded were also divided.

Conclusions: There was general support for dose-banding, but concerns about the lack of an evidence base could be a barrier to the wider introduction of the system. Consequently, more clinical studies are required to justify the safety and efficacy of dose-banding, and also to evaluate whether dose-banding is acceptable within clinical trials. Kaestner, S. A., Sewell G. J. (2009). Clinical Oncology 21, 320-328
\end{abstract}

(c) 2009 The Royal College of Radiologists. Published by Elsevier Ltd. A.l rights reserved.

Key words: Chemotherapy, dose, dose-banding, prescribers, survey, UK

\section{Introduction}

Spiralling drug and treatment costs and an increased demand for chemotherapy services are key service delivery and economic drivers for the investigation of alternative strategies, such as dose-banding, in the provision of cancer services. The first published references to 'banding' of chemotherapy dosing appeared in the Pharmaceutical Journal in 1996 [1] and in 1998 when Baker and Jones [2] proposed placing patient body surface area (BSA) measurements into BSA bands to rationalise chemotherapy provision. In 2001, Plumridge and Sewell [3] defined 'dose-banding' as:

A system whereby, through agreement between prescribers and pharmacists, doses of intravenous cytotoxic drugs, calculated on an individualised basis, which are within defined ranges or bands, are approximated to pre-determined standard doses. The maximum variation of the adjustment between the standard dose and the doses constituting each band is $5 \%$ or less. A range of pre-filled syringes or infusions, manufactured by pharmacy staff or purchased from commercial sources, can then be used to administer the standard dose.

Dose-banding enables batch preparation of standard syringes or infusions. Batch preparation is only suitable for drugs with sufficient long-term drug stability [3,4], but allows end product quality control testing for drug assay and sterility [3]. The importance of assuring asepsis in chemotherapy given to immunocompromised patients should not be underestimated, because many cytotoxic infusions support the viability of micro-organisms [5-7]. Dose-banding therefore offers benefits to patient safety 
and infusion quality that are not possible with individualised doses, which are always used immediately after preparation.

Structured interviews performed in 2001 indicated that there was a positive opinion about dose-banding of cancer chemotherapy among oncology healthcare professionals [3]. The main reasons for this are probably the ability to plan the workload by using pre-filled chemotherapy syringes, which has been observed to reduce stress in the workplace for both oncology nurses and staff in pharmacy chemotherapy units, in addition to the ability to provide an improved service for patients by reducing waiting times $[2,3,8]$. Other proposed advantages of dosebanding include reduced chemotherapy preparation and administration errors $[3,9]$. Finally, reduced chemotherapy preparation times and drug wastage with dose-banding have been shown to reduce the costs of chemotherapy provision [10]. With the introduction of costly drugs, such as targeted monoclonal antibodies, the cost of drug wastage will clearly become more noticeable.

However, a recent (2006) National Cancer Network pharmacists survey suggested that no more than $26 \%$ of UK cancer centres use dose-banding for the provision of cancer chemotherapy and that in these centres, about $43 \%$ of suitable out-patient doses are dose-banded. Considering the potential advantages with dose-banding, this level of usage seems surprisingly low. The reasons for this low uptake may vary, but could include a lack of awareness of the system or a reluctance to use it for clinical reasons. The clinical evidence related to dose-banding is limited, with only one pharmacokinetic study performed to date [11]. Despite the fact that the science behind BSA-based chemotherapy dose individualisation has been questioned and the seemingly minor change from current established practice of preparing chemotherapy doses, dose-banding does have the potential to alter patient exposure to chemotherapy. The question of whether dose-banded chemotherapy may be used in clinical trials is a further issue. Increasing numbers of patients receive chemotherapy within the framework of a clinical trial, and since the National Cancer Research Network was established in 2001, the recruitment of cancer patients into trials has almost doubled [12]. The practical aspects of the implementation of dose-banding may also be seen as a hindrance. For example, the batch production of pre-filled chemotherapy syringes requires planning and organisation if these are to be manufactured within the hospital pharmacy. Also, the availability of sufficient refrigerated storage space is a prerequisite for the system to be practically viable. For hospitals that choose to purchase pre-filled syringes for dose-banding from commercial sources, this may not be such an issue. In either case, any benefits from the introduction of dose-banding will probably be most noticeable for frequently used regimens in busy oncology centres. The benefits for hospitals where relatively few patients are treated with chemotherapy may be limited.

Any changes in current practice and the introduction of new dosing systems, such as dose-banding, will probably only succeed with the support of consultant oncologists and haematologists, who are responsible for chemotherapy dose selection and prescribing. Prescribers are clearly key stakeholders in chemotherapy treatment and oncologists are seen as central to the development of cancer services in the NHS cancer plan [13].

The pharmacists interviewed by Plumridge and Sewell [3] perceived that the support from prescribers for the use of dose-banding would be as strong as $70 \%$ based on the following three factors:

- the potential for reduced patient waiting times;

- the limitation of dose variance to $5 \%$ or less from the prescribed dose;

- the belief that because BSA-based dosing was considered inaccurate by many, dose-banding was unlikely to affect toxicity or clinical outcomes.

Still, about $40 \%$ of the interviewed pharmacists were of the opinion that some oncologists may oppose dose-banding [3]. The reasons given to support this view were:

- the variance introduced by dose-banding, when combined with the pre-existing inaccuracies in BSA-based dosing, would result in an unacceptable total variance from the prescribed dose;

- oncologists want 'clinical freedom' in their prescribing practice;

- prescribers may not be aware of the practical issues associated with the provision of patient-specific chemotherapy doses.

However, at that stage there were no discussions on dose-banding that actually involved oncologists and haematologists, and no previous publications on dose-banding have included the views of chemotherapy prescribers either $[2,8,14]$. Simultaneously, anecdotal evidence suggests that the reason dose-banding has not been introduced in the USA and some European countries is mainly the resistance by prescribers to deviate from the use of exact, patientspecific chemotherapy doses, usually calculated from BSA. This clearly indicates the need for studies to establish the current awareness of prescribers about dose-banding, and their opinions on the changes it introduces to chemotherapy dosing and the scope and limitations of dose-banding in the context of UK chemotherapy services. The purpose of this study was to address this need through a survey of UK chemotherapy prescribers.

\section{Materials and Methods}

In order to identify the key issues and, hence, the important questions to be asked of prescribers, two different focus group meetings with oncologists were set up. Both focus groups began with a short presentation by the authors summarising the current evidence and experiences related to dose-banding. These included the advantages described in the introduction, which were reduced patient waiting times, improved workload planning for 
pharmacy staff and cost savings. In addition, preliminary data from the first pharmacokinetic study [11] comparing dose-banding with patient-specific dosing in terms of exposure to 5 -fluorouracil were presented. Free discussion was then encouraged and the oncologists were invited to identify what they considered to be the important issues.

The issues raised were consistent between the two focus groups, but were quite diverse in their nature, ranging from the scientific basis for chemotherapy dosing to financial management. The focus groups identified awareness as a key issue and whether the majority of prescribers were familiar with dose-banding and understood its difference from arbitrary dose rounding, where doses are arbitrarily rounded up or down to the nearest 1,5 or $10 \mathrm{mg}$, which is common in clinical practice. Regional differences in the familiarity with and use of dose-banding were also of interest. For those prescribers who were opposed to the system it was felt essential to establish the reasons for this, for example whether it was related to the 'rationalisation' of chemotherapy dosing and the discontinuation of exact BSA-based dosing.

Another question that emerged was the support or otherwise for dose-banding of non-BSA-dosed chemotherapy drugs, such as carboplatin and monoclonal antibodies. As the latter group includes high-cost drugs, the use of dose-banding could offer significant savings. In addition, there were differing opinions on the causes for delays in the provision of out-patient chemotherapy, and participants felt it would be interesting to determine these on a national basis.

It became clear that a national survey throughout the UK was necessary. In view of the complexity of some of the issues raised, the use of structured interviews with prescribers would be the optimal method for obtaining the required information. However, because of the limited accessibility to oncologists and haematologists and the difficulty in covering a wide geographical area with this approach, a postal questionnaire was considered the most favourable option.

To maximise response rates, the questionnaire was intentionally kept short and was restricted to the questions considered most important by the focus groups. It was preceded by a brief introduction to describe dosebanding and to distinguish it from dose rounding. Before national distribution, the questionnaire was validated for face validity, content validity and read repeatability (reliability). The face validity is a subjective evaluation of the questionnaire content and appropriateness of the questions in the considered target group, whereas an assessment of content validity ensures that there is a focus on the questions that are most essential to the subject. The read repeatability evaluation verifies that the interpretation of the questions is similar between respondents [15]. This validation was performed by evaluating the responses and comments obtained in a pilot study of the questionnaire including both medical and clinical oncologists. All questions were interpreted identically by the 18 respondents in the pilot and therefore no further changes were made. The final version of the questionnaire (see Table 1) consisted of two A4 pages and included eight questions.

The survey fell within the definition of a clinical audit [16] and therefore no ethics or research and development approvals were required.

Contact details for oncologists practising in the UK were obtained from the 2006 Directory of Cancer Care [17]. The distribution list was screened to eliminate multiple mailings to individual practitioners with affiliation to more than one hospital trust. The questionnaire was then distributed via post to 1104 oncologists, haematologists and paediatric oncologists throughout the UK during December 2006. Data collection continued until 20 March 2007.

A database (Microsoft Excel) was created for the entry and analysis of questionnaire data. In view of the demographic variations in the provision of cancer services, including differences in the operation of cancer networks, data analysis focused on presenting the information in a concise, understandable format to inform service development and research priorities in dose-banding. Detailed statistical analysis was not considered appropriate or necessary to support the conclusions reached in this study.

For demographic assessment, the responses were grouped according to Strategic Health Authorities for England [18], whereas responses for Scotland, Northern Ireland and Wales were grouped separately as geographical regions.

\section{Results \\ Demographics for the Respondents}

The response rate to the 1104 posted questionnaires was $35 \%$ (387 responses), of which $98 \%$ (379) were evaluable. Figure 1 shows the regional distribution of the respondents divided into the English Strategic Health Authority regions, Wales, Northern Ireland and Scotland. The classification of respondents according to speciality and duration of post held are presented in Fig. 2.

Although it is not possible to claim that the respondents to this survey were a true reflection of the population of chemotherapy prescribers across the UK, reference to Fig. 1 shows that all UK health regions were represented. The response rates across regions varied from between 23\% (South Central) to $44 \%$ (South East Coast), with a median response rate of $34 \%$. Also, as Fig. 2 shows, the main clinical specialities that prescribed chemotherapy were represented and respondents exhibited a wide range of experience at consultant level.

\section{Responses to Specific Questionnaire Questions}

The responses to questions $1-7$ of the questionnaire are summarised numerically and as percentages in Table 1. These data are analysed in further detail in the Discussion section, together with selected qualitative responses and a selection of the responses to question 8 (qualitative and open ended). 
Table 1 - Summary of responses to the questionnaire

\begin{tabular}{|c|c|c|c|c|}
\hline Question & Yes & No & I do not know/probably & No response \\
\hline $\begin{array}{l}\text { 1. Do you have concerns about the time out-patients } \\
\text { have to wait? }\end{array}$ & $281(74 \%)$ & $93(25 \%)$ & $5(1 \%)$ & - \\
\hline 2. Have you heard about dose-banding previously? & $308(81 \%)$ & $71(19 \%)$ & - & - \\
\hline 3. Does your hospital use dose-banding? & $238(63 \%)$ & $83(22 \%)$ & $20(5 \%)$ & $38(10 \%)$ \\
\hline 4. Do you think dose-banding is sensible? & $308(81 \%)$ & $\begin{array}{l}10(3 \%) \\
\text { (reluctant) }\end{array}$ & $55(15 \%)$ & $6(2 \%)$ \\
\hline $\begin{array}{l}\text { 5. Do you think there are benefits with dose-banding? } \\
\text { 6. Which do you think the maximum deviation from the } \\
\text { individualised dose should be? }\end{array}$ & $349(92 \%)$ & $4(1 \%)$ & $7(2 \%)$ & $19(5 \%)$ \\
\hline$<5 \%$ & $197(52 \%)$ & & & $7(2 \%)$ \\
\hline$<10 \%$ & $150(40 \%)$ & & & \\
\hline$<15 \%$ & $8(2 \%)$ & & & \\
\hline Other/do not know & $17(4 \%)$ & & & \\
\hline \multicolumn{5}{|l|}{$\begin{array}{l}\text { 7. Would it be acceptable to dose-band drugs with non-body } \\
\text { surface area-based dose? }\end{array}$} \\
\hline Carboplatin & $203(54 \%)$ & $79(21 \%)$ & $70(18 \%)$ & $27(7 \%)$ \\
\hline Targeted antibodies & $232(61 \%)$ & $37(10 \%)$ & $72(19 \%)$ & $38(10 \%)$ \\
\hline $\begin{array}{l}\text { 8. Are there any additional issues on chemotherapy provision } \\
\text { or 'dose-banding' you would like to mention or comment on? }\end{array}$ & See Discussion & & & \\
\hline
\end{tabular}

\section{Discussion}

\section{Response Rate, Distribution of Respondents and Awareness of Dose-Banding}

There was a similar proportion of responses from prescribers who had held their consultant posts for 0-5, 5-10, $10-15$ and $>15$ years $(22,30,20$ and $28 \%$, respectively). This was important for detecting any potential differences in opinions between prescribers of different clinical experience. The number of respondents varied between each speciality, with response rates from clinical oncologists, medical oncologists, haematologists, paediatric oncologists and 'others' of $36,61,46,33$ and $2 \%$, respectively,

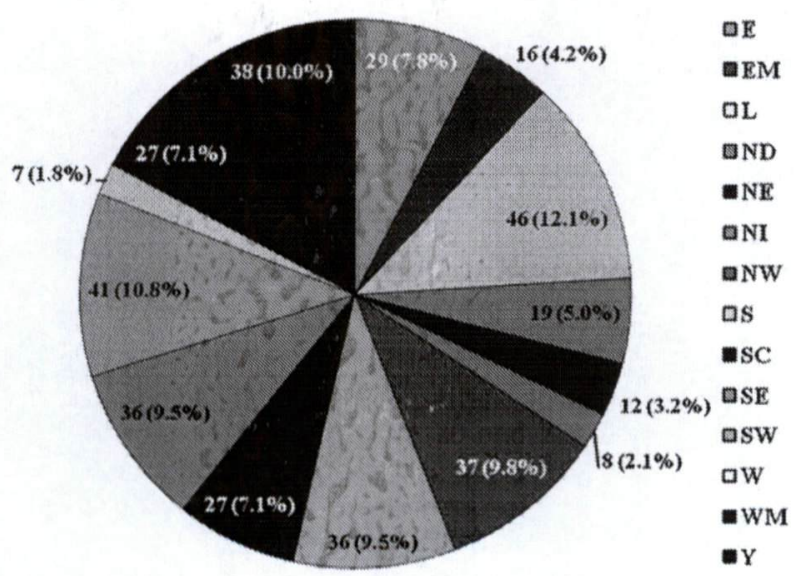

Fig. 1 - Number of respondents from each health region. E, East of England; EM, East Midlands; L, London; ND, not defined; NE, North East; NI, Northern Ireland; NW, North West; S, Scotland; SC, South Central; SE, South East Coast; SW, South West; W, Wales; WM, West Midlands; $Y$, Yorkshire and The Humber. where the 'others' category included cancer surgeons, palliative care specialists and urologists. In numerical terms, most responses were obtained from clinical oncologists. The main groups of chemotherapy prescribers were represented in this response.

The total response rate of $35 \%$ exceeded the expectations of the investigators and participants of the focus groups. A second mailing to non-responders was considered unlikely to significantly improve this response rate and, as discussed later, would not reduce the risk of bias.

As shown in Table 1, $238(63 \%)$ of the prescribers reported that dose-banding was used in their hospital, whereas 20 (5\%) did not know if it was. This reported level of usage seems high compared with the $26 \%$ usage reported in the Cancer Network pharmacists' survey. This may indicate that the response rate in the current study was biased, with a higher number of prescribers who are familiar with the

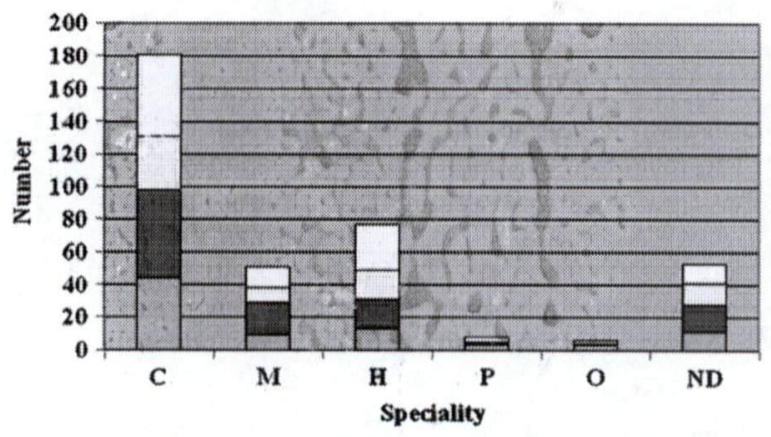

$\square>15$ years 0 10-15 years $\$ .10$ years $00-5$ years

Fig. 2 - Number of respondents divided into speciality and years in consultant post. C, clinical oncologist; $M$, medical oncologist; $\mathrm{H}$, haematologist; $\mathrm{P}$, paediatrician oncologist; $\mathrm{O}$, other; ND, not defined. 
system responding. However, it is also important to note that the responses in the current study reflect individual prescribers and not cancer centres. Another factor contributing to the difference may be that the demographics of the Cancer Network survey coverage did not map on to this study.

Table 1 shows that 281 (74\%) prescribers were concerned about how long patients wait to receive their chemotherapy in their hospital, and this result is presented for each specific region in Fig. 3. The response varied from $100 \%$ concerned (Wales) to 59\% (West Midlands). However, the number of responses from Wales was low.

Of those who were concerned about patient waiting times, 101 (36\%) gave their opinions on the main causes for treatment delays. 50 ( $18 \%$ of those concerned) mentioned chemotherapy preparation by the pharmacy, whereas 36 $(13 \%)$ and $15(5 \%)$, respectively, suggested the wait for blood count results and the lack of space.

Prescriber awareness of dose-banding was variable and, for example, $32 \%$ of the responding haematologists had not previously heard about dose-banding, whereas 13 and $4 \%$ of the clinical and medical oncologists, respectively, had not previously heard about the system. The experience of respondents at the consultant level did not seem to affect the familiarity with dose-banding, as about $20 \%$ in each group $(0-5,5-10,10-15$ and $>15$ years $)$ had not previously heard about the system. Figure 4 shows the numbers and percentages of respondents in each region who were aware of dose-banding. The Northern Ireland oncologists were least aware (50\%, but with a low number of respondents), whereas those in Scotland were most aware (94\%). Many factors could account for regional differences in the familiarity with dosebanding, including networking of prescribers and specialist pharmacists, sharing of treatment protocols and staff working at more than one hospital.

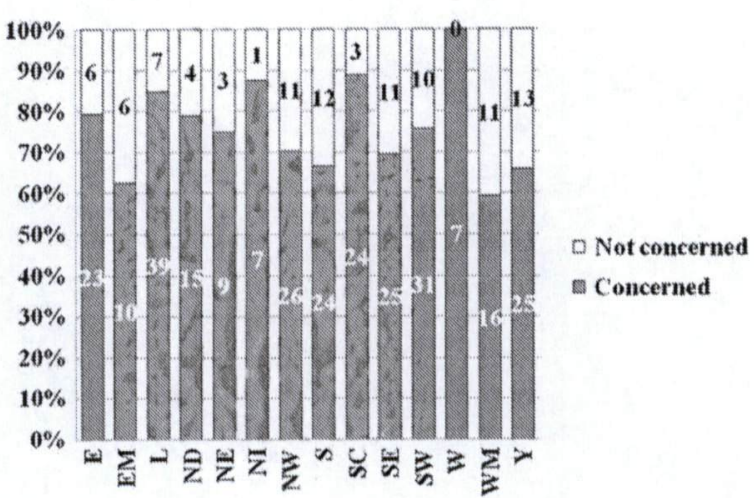

Fig. 3 - Percentage and number of prescribers concerned about the time patients in their hospital wait to receive chemotherapy. $\mathrm{E}$, East of England; EM, East Midlands; L, London; ND, not defined; NE, North East; NI, Northern Ireland; NW, North West; S, Scotland; SC, South Central; SE, South East Coast; SW, South West; W, Wales; WM, West Midlands; $Y$, Yorkshire and The Humber.

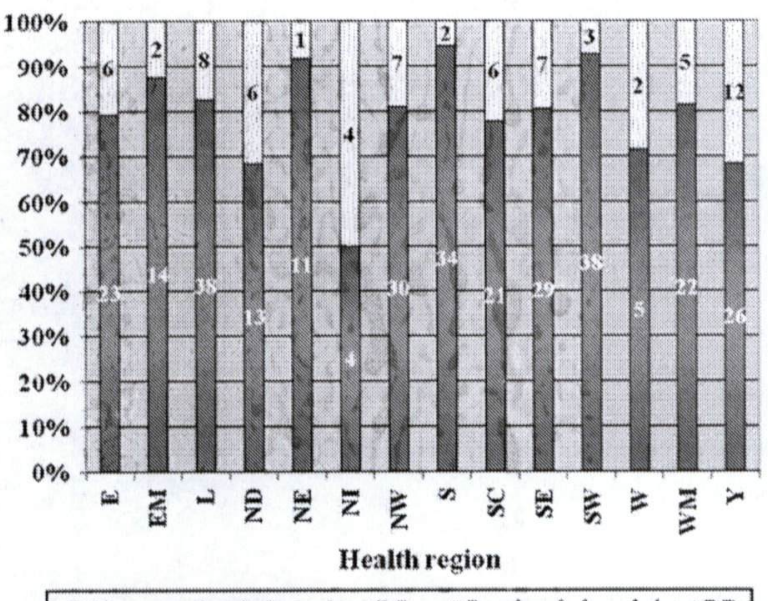

aDid not previously hear about $\mathrm{DB} \quad \mathrm{EPrevionsly}$ heard about $\mathrm{DB}$

Fig. 4 - Percentage and number of respondents familiar with dosebanding (DB) according to region. E, East of England; EM, East Midlands; L, London; ND, not defined; NE, North East; NI, Northern Ireland; NW, North West; S, Scotland; SC, South Central; SE, South East Coast; SW, South West; W, Wales; WM, West Midlands; Y, Yorkshire and The Humber.

Table 1 shows that $308(81 \%)$ of the respondents thought that dose-banding is a sensible way to rationalise chemotherapy dosing. Except for previously mentioned benefits with the system, several mentioned that dose-banding would reduce compounding errors and lead to increased safety. Some, however, were less certain and 55 prescribers (15\%) were of the opinion that dose-banding is 'probably' a good strategy, whereas $10(3 \%)$ would be reluctant to use it. Of those who had not previously heard about dosebanding, $49(69 \%)$ supported the system, whereas $14(20 \%)$ were unsure and $7(10 \%)$ did not support the system. Some justifications for this lack of support were given as qualitative responses as cited below:

- 'Small changes in dose may be toxic or have less efficacy'

- 'I would be worried about under-dosing in some patients'

- 'What about subsequent dose modifications?'

- 'I am not sure, are there outcome data from specified cancer types/treatment regimens?'

- 'I prefer to dose according to surface area unless there is a good evidence base to show that dose-banding does not affect outcome'.

Of the respondents who were familiar with dose-banding, three (1\%) did not support the system. Justifications for this were that 'it is not applicable for some trials and is potentially imprecise', and that 'no work is done where long-term results are available'. Also, paediatric oncologists did not support the system, due to the larger variability in body size between children, and because the benefits of dose-banding may be limited in paediatrics due to the smaller patient group and widely variable doses. 
Of the four respondents $(1 \%)$ who were of the opinion that there are no benefits with dose-banding, the following comments were offered to support their view:

- 'What matters is dose intensity. It has been shown that sub-optimal dose intensity compromises response rates - this is generally accepted. My concern is that dose-banding may reduce dose intensity for some patients and this might be important'.

- 'Expiry time limits for pre-prepared doses and could increase drug wastage'.

- 'Benefits for pharmacists but (probably) not for patients'.

\section{Maximum Deviation from Prescribed Dose}

The number of prescribers supporting a 5 or $10 \%$ maximum deviation from the exact individualised BSA-based dose were similar, and were $197(52 \%)$ and $150(40 \%)$, respectively, as presented in Table 1. In Fig. 5, these numbers are shown according to speciality. Deviations of up to $15 \%$ were supported by a larger percentage of medical oncologists compared with the other specialities. This may have been because this group would be expected to have greater expertise in the pharmacology of cancer chemotherapy and may have a greater familiarity with the limitations surrounding current practice in dose calculation.

Selected comments in response to the question regarding acceptable maximum deviation from the prescribed dose were:

- 'Would need more evidence as to whether $10 \%$ is safe'

- 'May depend on the drug in question'

- 'If possible should be evidence based, however $10 \%$ would seem reasonable'

- ' $10 \%, \mathrm{BSA}$ is not clearly effective chemotherapy dose'.

The qualitative responses provided to questions 4,5 and 6 clearly show the concerns among prescribers about the paucity of clinical and pharmaceutical evidence available to support dose-banding.

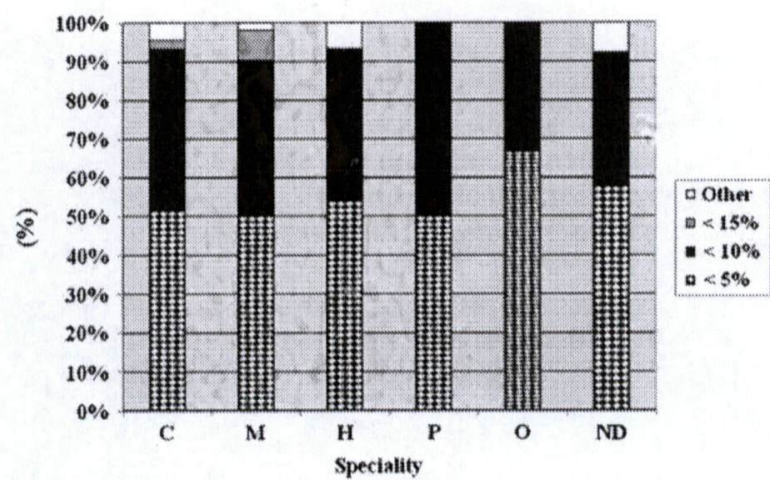

Fig. 5 - Opinions on acceptable maximum deviation from exact body surface area-based dose according to speciality. C, clinical oncologist; $M$, medical oncologist; $H$, haematologist; $P$, paediatrician oncologist; $\mathrm{O}$, other; ND, not defined.

\section{Dose-Banding of Carboplatin}

Although 203 responders (54\%) would support dose-banding of carboplatin, as shown in Table 1, 79 (21\%) were opposed to it, whereas $70(18 \%)$ did not know or thought that it probably would be acceptable and $27(7 \%)$ did not respond. This result is presented according to speciality in Fig. 6. There were no clear trends in opinion associated with length of experience among prescribers (data not presented). The medical oncologists, although more likely to be supportive of wider variation from the prescribed dose in the application of dose-banding to BSA-dosed drugs, were more conservative in their support for dose-banding of carboplatin.

Obviously, dosing of carboplatin according to renal function (glomerular filtration rate; GFR) is considered as more accurate than BSA-based dosing, which may partly explain the reluctance to immediately accept dose-banding of this drug. Although the most important factors affecting drug pharmacokinetics, for example the metabolic capacity of specific enzymes and/or renal function, are not accounted for in BSA-based dosing [19], carboplatin is dosed according to a strategy that offers reduced pharmacokinetic variability [20]. Dose-banding of BSA doses is therefore less likely to influence the variability in drug exposure of both healthy and tumour tissue than dosebanding of GFR-based carboplatin doses, where the introduction of an additional random error could be of clinical significance $[20,21]$.

Some selected comments in favour of carboplatin dosebanding from question $7(\mathrm{a})$ on the questionnaire were:

- 'provided that it is within 5\% of the estimated dose'

- 'provided that the patient is not old and has comorbidities or poor renal function to start with'

'yes, as creatinine clearance also has a wide error band'

- 'yes, providing dose is calculated with [Calvert] formula'

Among the comments made by respondents who did not support dose-banding of carboplatin, or were unsure, were, for example:

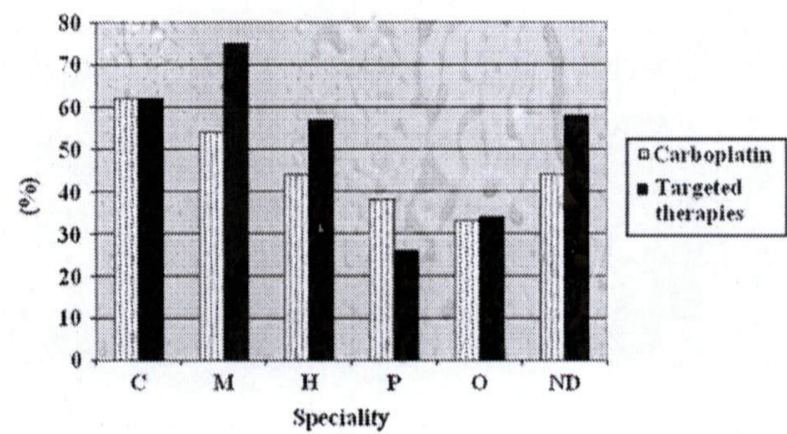

Fig. 6 - Percentages supporting dose-banding of carboplatin and targeted therapies according to speciality. C, clinical oncologist; $M$, medical oncologist; $\mathrm{H}$, haematologist; $\mathrm{P}$, paediatrician oncologist; 0 , other; ND, not defined. 
- 'GFR measurement can vary'

- 'dosing depends on GFR each cycle'

- 'would need looking at potential inaccuracies/problems'

- 'not sure of evidence either way'.

\section{Dose-Banding of Targeted Therapies}

The application of dose-banding to targeted therapies is likely to be complex, because unlike other dose-banded drugs, it is not yet possible to prepare the standard doses in advance. Monoclonal antibodies are complex proteins with three-dimensional secondary and tertiary structures, which are formed from intra-molecular hydrogen bonding. These protein conformations may need to be intact to retain biological activity, and the reconstituted solutions must therefore be used immediately after preparation. The difficulties in assessing the stability of these agents by conventional physical and chemical methods have already been recognised [22]. However, some trusts have introduced dose-banding to whole vials of, for example, trastuzumab, to reduce drug wastage.

The responses indicated that $232(61 \%)$ were in favour of dose-banding of targeted therapies, whereas $37(10 \%)$ and 72 (19\%) were opposed to it or did not know, respectively. Compared with the opinion on carboplatin dose-banding, this seems to reflect the fact that body weight-based dosing of antibodies may not be considered as accurate as GFRbased dosing of carboplatin. Also, it is likely that the potential savings by using dose-banding for these expensive drugs have been considered an important priority, particularly by those consultants with managerial responsibilities (i.e. clinical directors). The opinions on dose-banding of targeted therapies are shown according to speciality in Fig. 6.

Selected comments in favour of dose-banding of targeted therapies were:

- 'especially to reduce wastage'

- 'we still probably need to look closely at choice of current dose'

- 'use "whole vial" doses to reduce wastage'

- 'biological drugs less dose specific'

- 'rituximab dose-banding has been used safely'.

No respondent opposing dose-banding of targeted therapies offered any comments.

\section{Qualitative Comments on Chemotherapy Provision and Dose-Banding}

Qualitative comments in response to question 8 of the questionnaire (see Table 1 ) were offered by $90(24 \%)$ of the responding prescribers. These comments were organised by the investigators into three categories to represent views on dose-banding: supportive, cautious and opposed. Most comments were supportive (65), whereas 20 and 5 were cautious or opposed, respectively. In general, supportive comments were justified by the questionable accuracy of BSA dosing, the need for national guidelines on chemotherapy dosing issues and the time savings introduced by dose-banding. Most of the comments of a cautious or opposed nature were made by prescribers who were supportive of dose-banding in general, but who were concerned by the potential for under-dosing and reduced dose intensity, and the lack of clinical trial evidence comparing dose-banding with individualised doses. Some comments also concerned the potential for overdosing and toxicity, for example in fragile patients or in patients receiving anthracyclines, where cumulative lifetime doses should not be exceeded. Some representative samples of all comments are presented below.

\section{Supportive of dose-banding}

'Another good way to equalise treatment across the country'

'Should be introduced in all trusts'

'It would always be a major step forward if this could be agreed nationally as the standard since the current BSA methods have shaky basis anyway. So banding is OK'

'Exact chemo doses on BSA are nonsense, takes no account of pharmacokinetics (dynamics) may as well round up/down to make easier'

'The "correct" dose is somewhat arbitrary in any case. Hence, for the benefit obtained with banding within $5 \%$ is perfectly acceptable'

'Tablets are dose-banded!'

'Chemo delivery is such an imprecise art (say 10-20\%) that it is probably reasonable to prescribe within certain limits'

\section{Cautious about dose-banding}

'What is the view of NCRI trials on dose-banding?'

'Depends on treatment intent, future research (randomised controlled trials)'

\section{Opposed to dose-banding}

'Should not distract attention from factors affecting individual patient tolerance'

\section{Limitations of this Study}

It is recognised that the questionnaire distributed in this study was designed mainly around the needs of oncologists. Although haematologists were not represented in either of the focus groups, many of the prescribing issues are the same (e.g. use of BSA dosing). Also, clinicians involved in the prescribing of chemotherapy for non-malignant diseases were excluded. Ideally, the questionnaire would have been administered in face-to-face interviews. However, the investigators recognised that this would be unrealistic, given the frenetic nature of UK oncology and haematology practice.

The response rate of $35 \%$ in this study was of a similar order to response rates previously obtained in postal surveys of US haematologists and oncologists [23] and UK clinical oncologists [24], with evaluable responses of 38 and 
$46 \%$, respectively. Although this result was considered satisfactory for a mail survey of this particular design, it is not straightforward to judge what is adequate for this type of study from a statistical perspective, as this depends on the differences between responders and non-responders [25]. Although a second mailing of the questionnaire to non-responders was considered, this was only expected to increase the response rate marginally [26] and the expected benefits could not justify the additional costs incurred. In addition, it has been previously shown that the value of testing for non-response bias by comparing early and late responders is limited [27]. This suggests that those with an interest in the topic are more likely to respond and that the non-responding group is unlikely to be reached despite additional reminders, a scenario in which the overall study conclusions would not be altered despite a slight increase in the response rate. In the case of this study, it may be argued that the $35 \%$ response rate 'selected out' those prescribers with an interest in, or who were supportive of, dose-banding. This is a possibility, but in the view of the investigators, consultant physicians would normally be equally generous with their opinions in opposition to a system as when supporting it.

Furthermore, because the questionnaire had a qualitative aspect in that it contained open-ended questions, the study can be considered to belong to the category of 'mixed methods research' [28], where much smaller sample sizes than those required in quantitative research studies are usually regarded as sufficient. In qualitative research, sample collection is usually discontinued when theoretical data saturation, the point at which no new relevant information is obtained, has been reached [29]. Often, data saturation is achieved with only a limited number of participants $[28,30]$. As all of the qualitative comments received in the current study could be represented by the comments described in the three categories above, the conclusion was that additional responses were unlikely to add differing viewpoints.

\section{Conclusions}

The aim of this UK-wide postal survey was to investigate the opinions and clinical judgements of chemotherapy prescribers, as these are factors that will probably be crucial to the uptake of dose-banding or any other chemotherapy dosing strategy. Although limited response rates generally have to be accepted due to the time constraints of healthcare professionals, postal survey results can give useful information. In this study, the views of 379 chemotherapy prescribers were obtained.

Overall, the audit identified a high level of awareness among UK chemotherapy prescribers about dose-banding of chemotherapy ( $>80 \%$ ). Many prescribers were familiar with the limited scientific rationale to support BSA-based dosing and were in favour of dose-banding. In addition, almost three-quarters of respondents were concerned about treatment delays for chemotherapy out-patients.

Several areas of controversy, where opinion was divided, emerged from this study. These included the maximum variation from the prescribed dose that should be permitted, and whether or not non-BSA-dosed drugs could be included in dose-banding schemes. The support for dosebanding of drugs dosed according to BSA generally seems stronger than that for dose-banding of carboplatin, which is dosed according to renal function.

A number of respondents called for evidence to support the effectiveness and safety of dose-banding. A clinical and pharmacokinetic crossover study with 5 -fluorouracil has indicated that dose-banding does not affect the exposure of tissues to this particular drug [11], but there is clearly a compelling, if belated, need for more clinical studies to evaluate the safety and efficacy of the system. Studies are also required to determine whether or not dose-banding is acceptable within the framework of clinical trials, particularly if these include a pharmacokinetic component. The lack of an evidence base seems a barrier to the development of guidelines and the wider introduction of dose-banding into clinical practice. Cancer network co-operation will also be crucial to facilitate the harmonisation of dose-banding schemes and the implementation of national guidelines for dose-banding. This would encourage the pharmaceutical industry to provide standard ranges of licensed pre-filled syringes with widely used chemotherapy drugs.

A wider understanding of which drugs and treatment settings are likely to derive the most benefit from dosebanding is also desirable. Dose-banding could be applied for targeted therapies for which drug wastage is costly. However, this is not only dependent on clinical studies, but also on formulation and stability studies that enable the manufacture of pre-filled syringes or infusions. In the future, the practice of dose-banding could also be extended to other drug classes with defined dosage regimens, such as intravenous antibiocics.

Other future research topics of relevance include studies on the effects of dose-banding on pharmacy compounding errors, drug administration errors and treatment complications, in addition to evaluations of patient and nurse preferences and the effect of dose-banding on occupational exposure of pharmacy and nursing staff to cytotoxic drugs.

Acknowledgements. The authors wish to thank all chemotherapy prescribers who helped with their contributions to this research.

Author for correspondence: S. A. Kaestner, Plymouth Teaching PCT, Medicines Management Team, Building One, Derriford Business Park, Plymouth, PL6 5QZ, UK. Tel: +44-7920465115; E-mail: s.kaestner@hotmail.co.uk

Received 23 April 2008; received in revised form 1 December 2008; accepted 3 December 2008

\section{References}

1 Anon. Development of a dose-banding system. Pharm J 1996; 256:297.

2 Baker JP, Jones SE. Rationalisation of chemotherapy services in the University Hospital Birrningham NHS Trust. J Oncol Pharm Pract 1998;4:10-14. 
3 Plumridge R, Sewell GJ. Dose-banding of cytotoxic drugs: a new concept in cancer chemotherapy. Am J Health-Syst Pharm 2001; 58:1760-1764.

4 Kaestner S, Sewell G. A sequential temperature cycling study for the investigation of carboplatin infusion stability to facilitate 'dose-banding'. J Oncol Pharm Pract 2007;13: 119-126.

5 Krämer I. Viability of microorganisms in novel antineoplastic and antiviral drug solutions. J Oncol Pharm Pract 1998;4:32-37.

6 Paris I, Paci A, Rey JB, Bourget P. Microbial growth tests in antineoplastic injectable solutions. J Oncol Pharm Pract 2005;11: 7-12.

7 Holmes CJ, Kubey WY, Love DI. Viability of microorganisms in fluorouracil and cisplatin small-volume injections. Am J Hosp Pharm 1988;45:1089-1091.

8 So J. Improving the lives of patients with cancer. Pharm Manage 2002;18:27-29.

9 Tran $M$. The impact of introducing pre-printed chemotherapy medication charts to a day chemotherapy unit. $J$ Oncol Pharm Pract 2000;6:64-69.

10 Kaestner S, Sewell G. Pharmacoeconomic aspects of dosebanding. Hosp Pharm Eur 2006;26:33-34.

11 Kaestner S, Walker V, Perren T, Sewell G. Pharmacokinetic assessment of "dose-banded" cancer chemotherapy. Pharmacotherapy 2005;25:1545 (abstract).

12 National Cancer Research Network, Available from: http:// www.ncrn.org.uk/ (accessed November 2008).

13 Department of Health. The NHS cancer plan. Stationery Office; 2000.

14 MacLean F, Maclntyre J, McDade J, Moyes D. Dose-banding of chemotherapy in the Edinburgh Cancer Centre. Pharm J 2003; 270:691-693.

15 Lowe D. Planning for medical research. A practical guide to research methods. Congleton: Astraglobe; 1993.

16 Differentiating audit, service evaluation and research. London: COREC ethics consultation E-group. Available from: www.corec. org.uk/applicants/help/docs/ls_and_As_Differentiating Research.pdf; July 2006 (accessed November 2006).

17 Directory of cancer care. Loughborough: CMA Medical Data; 2006.
18 NHS in England. Strategic health authorities, Available from: http://www.nhs.uk/England/AuthoritiesTrusts/Sha/Default. aspx (accessed December 2006).

19 Kaestner S, Sewell G. Chemotherapy dosing part I: scientific basis for current practice and use of body surface area. Clin Oncol ( $R$ Coll Radiol) 2007;19:23-37.

20 Calvert AH, Newell DR, Gumbrell LA, et al. Carboplatin dosage: prospective evaluation of a simple formula based on rena function. J Clin Oncol 1989;7:1748-1756.

21 Kaestner S, Sewell G. Dose-banding of carboplatin: rationale and proposed banding scheme. J Oncol Pharm Pract 2007;13: 109-117.

22 Astier A. The stability of anticancer drugs. Eur J Oncol Pharm 2007;1:21-23.

23 Streiff MB, Dundes L, Spivak JL. A mail survey of United States hematologists and oncologists: a comparison of business reply versus stamped return envelopes. J Clin Epidemiol 2001;54: $430-432$.

24 Jyothirmayi R, Coltart S. An audit of the indications for and techniques of palliative splenic radiotherapy in the UK. Clin Oncol (R Coll Radiol) 2005;17:192-194.

25 Young J. Mail surveys of general practice physicians: response rates and non-response bias. Swiss Med Wkly 2005;135: 187-188.

26 Asch $D$, Jedrziewski $M$, Christakis $N$. Response rates to mail surveys published in medical journals. J Clin Epidemiol 1997;50: 1129-1136.

27 Bergk V, Gasse C, Schnell R, Haefeli W. Mail surveys: obsolescent model or valuable instrument in general practice researcn? Swiss Med Wkly 2005;135:189-191.

28 O'Cathain A, Murphy E, Nicholl J. Why, and how, mixed methods research is undertaken in health services research in England: a mixed methods study. BMC Health Serv Res 2007;7: 85.

29 Sandelowski M. Sample size in qualitative research. Res Nurs Health 1995;18:179-183.

30 Benstead K. What is valuable for specialist registrars to learn in order to become good consultant clinical oncologists? Clin Oncol ( $R$ Coll Radiol) 2006;18:549-554. 